\title{
A case of steinert disease. anesthesiologic considerations
}

Volume 7 Issue 6 - 2017

\section{Introduction}

Steinert Syndrome is an inherited autosomal dominant disease caused by a CTG repeat expansion in the DMPK (dystrophia myotonia protein kinase) gene on chromosome19q13. It leads to accumulation in ribonuclear inclusions in the nucleus, finally resulting in altered splicing of multiple genes encoding for chloride channel $\mathrm{ClC} 1$, insulin receptor, the cardiac troponin and the NR1 subunit of the N-methyl-Daspartate receptor. Its incidence is 1/10.000-20.000. Onset of clinical manifestations (it is mostly diagnosed at the age of 40-50 y.o.) and disease story depend on the total number of CTG- repeats.

Its clinical futures are: proximal lib weakness, axial, facial, pharyngeal and respiratory muscles impairment (restrictive lung disease), cataracts, cardiac conduction block and arrhythmia, cardiomyopathy, diabetes, endocrine disorders, slow gastric empty and drowsiness. ${ }^{1}$

Speaking about general anesthesia, risks include cardiac rhythm problems and sudden cardiac arrest (even if an implanted pacemaker or defibrillator is primarily placed). ${ }^{2}$ Post-operative complications can be mainly addressed to respiratory problems (atelectasis, pneumonia, acute ventilatory failure). ${ }^{3}$

Muscular diseases often represent a "bugbear" for anesthesiologists because of the serious morbidities (such Malignant hyperthermia) reported in patients undergoing general anesthesia. ${ }^{4}$ Even if there's not a clear consensus on the practice, a sane recommendation seems to use a "trigger-free" anesthetic technique in patients "at risk".

\section{Case report}

We briefly report the case of a female patient $46 y .0$. affected by Myotonic muscular dystrophy (Steinert Disease) who underwent a laparotomic hysterectomy. A 46-year-old female (height $165 \mathrm{~cm}$, weight $67 \mathrm{~kg}$ ) presented to emergency department for metrorrhagia and anemization due to the presence of unknown multiple uterine myomas. She has hemoglobin level of $6,6 \mathrm{~g} / \mathrm{dl}$ and she was admitted to Gynecologic ward for observation and preparation for surgery. She was scheduled to undergo laparotomic hysterectomy.

Her unique comorbidity was Steinert disease. She received the diagnosis ten years before, at the age of 36. She had impaired walking, problems in switching from sitting to standing position and abnormal movements of bilateral scapular region because of muscle weakness, light swallowing disorder, intrarotation of left feet with tendons retraction, impaired palpebral closing. Bilateral cataract, and light restrictive respiratory failure $\left(\mathrm{FEV} 1 / \mathrm{FVC}=91 \%, \mathrm{O}_{2}\right.$ sat $=97 \%$ ) had also been diagnosed. She had also a recent history of deep venous thrombosis (April 2015) treated with low molecular weight heparin for three months and then with ASA until hospital presentation. A venous Doppler performed some days before admission was negative.

Echocardiography and dynamic Holter ECG 24h were normal. Laboratory tests including glucose, electrolytes, gamma

\author{
Raffaella Di Pasquale \\ UOC Anestesia, Rianimazione e Terapia Intensiva,ASST Bergamo \\ est, Italy
}

Correspondence: Raffaella Di Pasquale, UOC Anestesia, Rianimazione e Terapia Intensiva, ASST Bergamo est, Ospedale Bolognini,Via Paderno 2I, 24068 Seriate (BG), Italy, Tel +39380 1274659, Email raffaella.dipasquale@asst_bergamoest.it

Received: October 18, 2016| Published: April 13, 2017

glutamyltransferase, creatin kinase and thyroid hormones were also normal. Hemoglobin reached a value of $11 \mathrm{~g} / \mathrm{dl}$ after administration of 4 Units red blood cells. She had just one surgery (appendicectomy) when she was 6years old. She also had MALLAMPATI Grade 3 with interdental space less than $3 \mathrm{~cm}$. The American Society of Anesthesiologists Physical Status was 2. We chose to administer to the patient a blended anesthesia consisting in epidural analgesia plus total intravenous anesthesia with rapid sequence induction.

The patient was not premedicated for avoiding the risk of sudden loss of muscular tone or acute respiratory failure. By the way she received proton pump inhibitors and serotonin 5-HT3 receptor antagonist in consideration of prolonged gastric emptying time and reduced bulbar reflexes. In sitting position, after complete monitoring (ECG, Non invasive blood pressure, pulsioxymetry) of the patient and administration of low flow oxigen $100 \%$ (4l/min) via facial mask, an epidural catheter at T11-T12 was easily placed.

Then the patient regained the supine position, defibrillator plaques were glued in case of heart pacing needed and she received a modified rapid sequence induction under General Electric neuromuscular transmission monitoring (NMT) and Entropy monitoring. A cerebral target infusion (TCI) of Propofol Schnider's model $(4 \mathrm{mcg} / \mathrm{ml})$ first and, 30seconds after, a Remifentanil Minto's model $(5 \mathrm{ng} / \mathrm{ml})$ was setted for achieving a depression in cerebral activity leading to a value of 40/70 (Response Entropy/State Entropy). Then first basal Train of four (TOF) stimulation on NMT was measured and set every 15 seconds. After that a bolus of rocuronium $1 \mathrm{mg} / \mathrm{Kg}$ was administered leading to a TOF of 0 in 57 seconds. Orotracheal intubation was easily performed with videolaringoscope.

Once the correct position of orotracheal tube was assessed an arterial line for invasive blood pressure was placed and body temperature via esophageal probe was measured; patient was also warmed with active blanket. Then the patient received an epidural bolus of ropivacaine $0,15 \% 10 \mathrm{ml}$ and TIVA/TCI was target to maintain an adequate grade 
of sedation. One hour after the epidural bolus we started an epidural infusion with ropivacaine $0,17 \% 8 \mathrm{ml} / \mathrm{h}$.

TOF reached $1 / 4$ at 81 minutes after the initial dose which coincided with the end of surgery. To rapidly and safely enhance the recovery of neuromuscular function we administered sugammadex $270 \mathrm{mg}$ $(4 \mathrm{mg} / \mathrm{Kg})$. At the same time Propofol TCI infusion was set at point 0 and Remifentanil at point 1 to achieve the patient to tolerate orotracheal intubation while awakening. NMT showed a TOF of four in 200seconds after the administration of the specific antagonist. At that point we also removed the esophageal temperature probe with last value $36,5^{\circ} \mathrm{C}$. We set the mechanical ventilator in pressure assisted mode (with volume guaranteed) and we saw the patient fully recovering respiratory function in a couple of minutes more. Entropy parallel showed the gradual recovery of consciousness. When she was able to follow commands, the respiratory rate was $<30$ breaths per minute with a tidal volume $>5 \mathrm{ml} / \mathrm{Kg}$ we extubated the patient uneventfully.

Then we brought the patient to the postoperative care unit for monitoring. Pain was well controlled and she didn't complained any notable weakness. She was discharged in the gynecologic ward 24hours later without complications.

\section{Discussion}

We now discuss the case of a 46years old patient with Steinert Syndrome who underwent an invasive surgical procedure. Locoregional techniques are highly recommended, if the type of surgery allows it, in patients with myotonic diseases because they avoid use of potential Malignant Hyperthermia trigger-drugs, orotracheal prolonged intubation with risk of respiratory failure and use of opiates as postoperative analgesia. Even if it's possible to perform a laparotomy with a lower midline incision under neuraxial anesthesia, we preferred different. We chose general anesthesia for the following reasons.

I. Pure neuraxial anesthesia seems an uncomfortable technic for a surgery in which deep organs are involved with associated risk to provoke unpleasant vagal reflexes. Mild sedation is contraindicated in patients with advanced stage disease.

II. It's reported that spontaneous tetanic contractions can happen due to a lot of causes, for example hypothermia, hyperkalemia, electric cauterization; we supposed if it could happen it would also not be very comfortable for the patient.

III. The same has to be said for guaranteeing the safety of airways. Because the patient has already a light impairment of swallowing function we wanted to be sure she can be adequately protected.

IV. We also wanted to protect the patient from any possible complication or stress during operation.

Therefore we chose rapid sequence induction and intubation because of the risk of aspiration pneumonia due to low tidal volume, inefficacy of swallowing reflex, laryngeal muscle weakness, and delayed excretion of gastric contents. Adequate reversal of muscle relaxation is important. We chose to do it without succinylcholine to avoid the administration of a drug that cause abnormal muscular contractions and subsequent increase of kalium blood concentrations with further risks of complication (as cardiac arrhythmias or malignant hyperthermia). So we used vecuronium, the only one non depolarizing musclerelaxant agent with a specific antagonist; the coupled vecuronium/sugammadex has been already safely used in cases like this one. ${ }^{6-11}$ Other drugs of this cluster need to be antagonized from neostigmine, a substance that can also lead to severe muscle weakness. ${ }^{12,13}$ We chose total intravenous anesthesia with the same intent.

\section{Acknowledgements}

None.

\section{Conflicts of interest}

Author declares there are no conflicts of interest.

\section{Funding}

None.

\section{References}

1. Veyckemans F, Scholtes JL. Myotonic dystrophies type 1 and 2. Ped Anaesth. 2013;23:794-803.

2. Marla F, Richard M, John W, Michael G, Practical suggestions for anesthetic management of a myotonic dystrophy patient. Myotonic Dystrophy Foundation, Toolkit.

3. Mathieu J, Allard P, Gobeil G, et al. Anesthetic and surgical complications in 219 cases of myotonic dystrophy. Neurology. 1997;49(6):1646-1650.

4. Gurnaney H, Brown A, Litman RS. Malignant hyperthermia and muscular dystrophies. Pediatr Anesth. 2009;109(4):1043-1048.

5. Davis PJ, Brandom BW. The association of malignant hyperthermia and unusual disease: when you're hot or maybe not. Anesth Analg . 2009;109(4):1001-1003

6. De Boer HD, Van Esmond J, Booij LH, et al. Reversal of rocuroniuminduced profound neuromuscular block by sugammadex in Duchenne muscular dystrophy. Paediatr Anesth. 2009;19(12):1226-1228.

7. Baumgartner PB. Rocuronium and sugammadex in myotonic dystrophy. Anaesth Intensive Care. 2010;38(5):959e60.

8. Petrovski J. The use of sugammadex to reverse rocuronium in a patient with myotonic dystrophy. Anaesth Intensive Care. 2011;39(3):505-506.

9. Galvez Canellas JL, Errando CL, Ordonez Arana A, et al. Sugammadex, efficacious in reversing a neuromuscular block in a woman with Becker muscular dystrophy. Rev Esp Anestesiol Reanim. 2011;58(10):614-617.

10. Shimauchi T, Yamaura K, Sugibe S, et al. Usefulness of sugammadex in a patient with Becker muscular dystrophy and dilated cardiomyopathy. Acta Anaesthesiologica Taiwanica. 2014;52(3):146-148.

11. Pellegrini L, Mercier F, Cornese A, et al. Rapid sequence induction in a patient with Steinert myotonic dystrophy: Interest of the association of high doses of rocuronium and sugammadex. Annales Françaises d'Anesthésie et de Re'animation. 2012;31:155-157.

12. Buzello W, Krieg N, Schlickewei A. Hazards of neostigmine in patients with neuromuscular disorders. Report of two cases. Br J Anaesth. 1982;54(5):529-534.

13. Owen PM, Chu C. Emergency caesarean section in a patient with myotonic dystrophy: a case of failed postoperative extubation in a patient with mild disease. Anaesth Intensive Care. 2011;39(2):293-298. 